\title{
P51. Identification of prostate cancer-associated antigens by oxygen manipulation
}

\author{
$\mathrm{T} \mathrm{Ma}^{1 *}$, A Elkhattouti ${ }^{1}$, F Kosari ${ }^{2}$, RJ Karnes ${ }^{3}$, JC Cheville ${ }^{4}$, G Vasmatzis ${ }^{2}$, S Vuk-Pavlovic ${ }^{5}$, RC Gomez ${ }^{1}$ \\ From 1st Immunotherapy of Cancer Conference (ITOC1) \\ Munich, Germany. 12-14 March 2014
}

\section{Background}

Therapeutic vaccination against prostate cancer $(\mathrm{CaP})$ remains marginally effective. A reason for failure may stem from the fact that vaccine cells are usually cultured in ordinary air. Solid tumours including $\mathrm{CaP}$ contain regions with oxygen deficiency (hypoxia) secondary to the lack of blood supply to the growing tumour nodules, which may lead to changes in expression of cancer-associated antigens in tumour cells. To test this hypothesis we determined whether oxygen-sensitive CaP-associated antigens in cultured $\mathrm{CaP}$ cell lines and human tumour tissues exist.

\section{Material and methods}

$\mathrm{LNCaP}$ and $\mathrm{VCaP}$ prostate cancer cells were propagated in culture media conditioned by the cells at normoxic $\left(20 \% \mathrm{O}_{2}\right)$ and hypoxic $\left(2 \% \mathrm{O}_{2}\right)$ environment. At first, we measured release of vascular endothelial growth factor (VEGF) by ELISA and the expression of VEGF- $\alpha$ mRNA by RT-PCR. To identify potential CaP-associated antigens, we prepared $\mathrm{CaP}$ cell lysates, resolved them by $2 \mathrm{D}$ electrophoresis and immunoblotting using spontaneous antibodies from plasma derived from $\mathrm{CaP}$ patients and control subjects. Antibody-labelled spots were analysed by MALDI-TOF mass spectrometry. Furthermore, we evaluated the expression of selected candidates in native CaP tissue.

\section{Results}

Hypoxic CaP cells released more VEGF $(\mathrm{P}<0.05)$ and expressed more mRNA for VEGF- $\alpha(\mathrm{p}<0.001)$ than normoxic cells. After two days of culture, hypoxic cells expressed some forty fold higher amount of VEGF transcripts compared to normoxic cells. CaP-associated spots identified in this study included heat shock protein
70 (HSP70), HSP60 and heterogeneous nuclear ribonucleoprotein L (hnRNP L). Among them, HSP70 and hnRNP L were $\mathrm{O}_{2}$-sensitive. Level of the two proteins were two times higher in $\mathrm{CaP}$ tissue than in control benign prostate tissue $(\mathrm{p}<0.05)$.

\section{Conclusion}

A unique set of $\mathrm{O}_{2}$-sensitive $\mathrm{CaP}$-associated antigens exist in $\mathrm{CaP}$ tumour tissues and spontaneous antibodies are detected in plasma derived from $\mathrm{CaP}$ patients. Therefore, CaP cells grown at hypoxic condition may provide a better antigen match to tumours in situ and may be more effective vaccines. (Supported by UMMC Incentive (to TMA), DOD PC094680 and PCF Creativity Award (to CRG).

\section{Authors' details \\ 'University of Mississippi Medical Center, Cancer Institute, Jackson, USA ${ }^{2}$ Mayo Clinic, Molecular Medicine, Rochester, MN, USA. ${ }^{3}$ Mayo Clinic, Urology, Rochester, MN, USA. ${ }^{4}$ Mayo Clinic, Laboratory Medicine and Pathology, Rochester, MN, USA. ${ }^{5}$ Mayo Clinic, Cancer Center and Internal Medicine, Rochester, MN, USA.}

Published: 12 March 2014

doi:10.1186/2051-1426-2-S2-P25

Cite this article as: Ma et al:: P51. Identification of prostate cancer-associated antigens by oxygen manipulation. Journal for ImmunoTherapy of Cancer 2014 2(Suppl 2):P25. 